\title{
Política externa planejada: os planos plurianuais e a ação internacional do Brasil, de Cardoso a Lula (1995-2008)
}

\author{
Planned Foreign Policy: Plurianual plans and Brazil's \\ international action, from Cardoso to Lula (1995-2008)
}

ANTÔNIO CARLOS LESSA*
LEANDRO FREITAS COUTO**
ROGÉRIO DE SOUZA FARIAS***

Rev. Bras. Polít. Int. 52 (1): 89-109 [2009]

\section{Introdução}

O Brasil tem uma sólida tradição em planejamento, que começou a ganhar corpo a partir da primeira metade do século passado. Desde o Plano Salte, no Governo de Eurico Gaspar Dutra (1946-1951), do Plano de Metas de Juscelino Kubitschek, (1956-1961) até os Planos Nacionais de Desenvolvimento (PNDs) da década de 1970, o país acumulou uma bagagem valiosa em termos de planejamento governamental que, dentro das estratégias de desenvolvimento nacional, sempre tiveram impactos no modo pelo qual o país se lançava ao mundo e definia suas prioridades para as relaçóes internacionais (ALMEIDA, 2004).

A partir do III Plano Nacional de Desenvolvimento - PND, que cobriu o mandato do último governo militar, de 1979 a 1985, e com o I Plano Nacional de Desenvolvimento da Nova República, que data de 1986, os principais instrumentos do planejamento federal passaram a representar documentos meramente formais. Com o ritmo inflacionário ganhando força, os planos e os orçamentos estatais, sem uma revisão periódica consistente, tornavam-se rapidamente peças declaratórias da reduzida capacidade de implementação do Estado brasileiro.

A Constituição de 1988 tentou resgatar a importância do planejamento, implementando os planos plurianuais (PPAs), hierarquicamente superiores e vinculantes às leis orçamentárias, e tornando crime de responsabilidade do presidente da República, sujeito à impedimento, o seu não envio ao Congresso

\footnotetext{
* Professor do Instituto de Relações Internacionais pela Universidade de Brasília (iREL-UnB) e pesquisador do Conselho Nacional de Desenvolvimento Científico e Tecnológico - CNPq (alessa@unb.br).

** Analista de Planejamento e Orçamento do Ministério do Planejamento, Orçamento e Gestão, Mestre e Doutorando em Relações Internacionais pela Universidade de Brasília - UnB (leandro.couto@gmail.com).

*** Especialista em Políticas Públicas do Ministério do Planejamento, Orçamento e Gestão, Mestre e Doutorando em Relações Internacionais pela Universidade de Brasília - UnB (rofarias@gmail.com).
} 
Nacional até do dia 31 de agosto do primeiro ano de governo. O primeiro plano feito nas novas bases, o Plano Plurianual 1991-1995, no entanto, foi elaborado com o objetivo principal de apenas cumprir os preceitos constitucionais, se revelando mais uma peça formal, conforme reconhece o próprio Ministério do Planejamento (MPOG, 2002).

É a partir de 1996 que os planos plurianuais passam não só a se constituir no principal elemento organizador da ação governamental, mas também a apresentar os grandes objetivos e delineamentos estratégicos a serem desenvolvidos para cada período de quatro anos. São eles os documentos herdeiros dos grandes planos que orientaram o estado desenvolvimentista das décadas de 1950 - 1970. Ainda assim, embora esses novos planos tenham ganhado espaço em artigos de revistas especializadas em economia e administração pública, os impactos dos projetos e ações neles delineados e as suas repercussões sobre a capacidade de ação internacional do país permaneceram desconhecidos para a área de relações internacionais, particularmente para aqueles interessados em política externa brasileira.

A relação entre os planos de governos e as relações exteriores é bastante óbvia. Como o modelo desenvolvimentista que esteve em voga no Brasil por boa parte do século XX, segundo aponta Cervo, concedia uma função supletiva ao setor externo no projeto de desenvolvimento nacional, isso teve reflexos na política externa brasileira que teve de se apropriar de determinadas características para desempenhar seu papel (CERVO \& BEUNO, 2002). A política externa deve ser vista como mais um meio a ser articulado para a busca dos objetivos maiores da nação explicitados no planejamento estatal. Ao se definir determinada estratégia de desenvolvimento a ser perseguida, a política externa cumpre seu papel buscando a mobilização de recursos externos, seja sob a forma de mecanismos de financiamento, seja pelo acesso a bens de capital ou tecnologias essenciais para o desenvolvimento industrial do país, por exemplo, ou mesmo na busca de mercados externos ou parceiros estratégicos para investir diretamente em setores considerados essenciais em determinado plano. Os planos terão, pois, invariavelmente, reflexos sobre as linhas de ação externa adotadas. Os planos de governo expressam as estratégias a serem adotadas e, nela, qual o papel que concedem à política externa no período específico. Como salienta Soares de Lima, a política externa "tem sido considerada como um dos principais instrumentos para propósitos de desenvolvimento" (SOARES DE LIMA, 2005).

Com isso, este artigo tem como objetivo central trazer à discussão das relaçôes internacionais e da política externa brasileira os planos plurianuais, desde o PPA 1996-1999 até o PPA 2008-2011. Busca-se apresentar as linhas estratégicas dos planos e como contemplam as relaçôes externas do país, dentro do quadro dos grandes objetivos e metas estipulados. Assim, procura-se investigar a coerência entre o planejado e o executado no período, que informa a validade do instrumento enquanto objeto de estudo da área. Por fim, permite perceber a racionalidade com a qual a política externa é concebida, como parte de um plano de desenvolvimento, 
ainda que se possa questionar seus pressupostos, bases ou seleção de objetivos. Trata-se de identificar o fio condutor das ações externas do país que as amarram ao núcleo de uma estratégia de desenvolvimento nacional. Investiga, portanto, se a política externa brasileira tem sido planejada em conjunto com as demais ações de governo, ou o quanto dessa importante política pública pode ser errática ou episódica.

\section{PPA 1996/1999 - Estabilidade econômica, modernização e a negligência da política externa}

O primeiro Plano Plurianual (PPA) pós-constituição de 1988 foi elaborado apenas como peça formal a cumprir os ordenamentos legais estabelecidos pela magna carta, abrangendo o período de 1991 a 1995. O PPA iria se transformar efetivamente em uma ferramenta de planejamento da ação estatal, entretanto, apenas após a estabilização monetária alcançada em 1994, com o Plano Real.

Sob a coordenação do então ministro do Planejamento José Serra, o Plano Plurianual 1996-1999 foi marcado pela priorização aos processos de estabilização econômica, reforma do Estado e desestatizações. Estabelecia como premissa básica a necessidade de consolidação da estabilidade, submetendo as políticas macroeconômicas e setoriais à política monetária. O plano é um retrato do pensamento liberal em voga na América Latina nos anos 90. Abertura comercial e desregulamentação estão entre as premissas básicas, que ainda direcionava ao setor privado parte substancial dos investimentos mais importantes previstos no plano, entre os quais os de infra-estrutura energética, que, por terem sido, em parte, frustrados, acabaram induzindo ao apagão energético do início dos anos 2000.

Três estratégias de ação convergiram para desenhar a estratégia de desenvolvimento que o país então adotava: construção de um Estado moderno e eficiente; redução dos desequilíbrios espaciais e sociais; inserção competitiva e modernização produtiva (MPOG, 1996). Esta última assentava-se na abertura da economia, qualificação da mão-de-obra, com atenção especial à educação básica, e à flexibilização das leis trabalhistas, enquanto a modernização do Estado estava associada à melhoria do corpo técnico de servidores.

A cada linha estratégica, associava-se um conjunto de diretrizes, no total de 23, que deveriam orientar os projetos e ações do plano. Em nenhuma delas, no entanto, faz-se qualquer menção às linhas de ação de política externa a serem priorizadas no período ou como a atuação externa do país estaria a serviço de seu desenvolvimento.

Todavia, isso não chegava a representar negligência ou incoerência do PPA com a política externa depreendida no período. Na visão de Amado Cervo, dando continuidade à ruptura empreendida por Fernando Collor de Melo, Cardoso consolidou uma política de abertura econômica como eixo diretor da ação internacional do Brasil, sem estratégia de inserção madura no mundo da 
interdependência global na ascenção do que chama de paradigma do Estado Normal no Brasil (CERVO, 2003b). Já Soares de Lima destaca, por seu turno, a existência de uma estratégia para obtenção da credibilidade internacional do país, na qual "a restauração da confiabilidade e da credibilidade internacionais está associada à vinculação da política externa à política econômica interna”, a qual seguia os princípios hegemônicos do Consenso de Washington (SOARES DE LIMA, 2005).

$\mathrm{Na}$ busca de uma participação ativa na vida internacional, nos organismos e regimes multilaterais, reverenciavam-se as fórmulas externas, mas alcançava-se uma inserção dependente. $\mathrm{Na}$ interpretação de Vigevani, a política externa do governo Cardoso procurou ter uma posição menos forte, de perfil mais moderado, "em que a ação externa se daria em um contexto de colaboração com iniciativas resultantes de órgãos internacionais, evitando assumir um papel internacional que resultasse em responsabilidades e riscos" (VIGEVANI \& CEPALUNI, 2007). A obtenção da credibilidade por meio da aplicação da agenda econômica pretensamente consensuada de então tornava incompatível uma postura externa mais assertiva em temas centrais.

Nesse ponto, a indefinição quanto às linhas estratégicas a serem seguidas pela política externa apresenta uma certa instrumentalidade. $\mathrm{O}$ ajuste aos ordenamentos externos, na aceitação dos preceitos de soberania compartilhada, conceito naturalmente aceito por Cardoso como mais uma face da inevitável onda globalizatória, era a ordem estratégica para a movimentação externa do país. O desenvolvimento não saía do horizonte da política externa, mas uma política externa autônoma não era vista como necessária para o alcance dos objetivos pretendidos. Bernal-Meza, em referência a Igor Fuser, coloca em termos de que "arquivada a idéia de um projeto autônomo de desenvolvimento nacional, restava ao país inserir-se passivamente na economia globalizada", destacando que o "estilo da política (de Cardoso) foi marcadamente de caráter passivo, conseqüência de problemas econômicos conjunturais e estruturais internos num contexto de crise econômica que se estendeu até os anos 2000 (BERNAL-MEZA, 2002).

Mais, portanto, que autonomia pela participação, o conceito apropriado pelo plano plurianual seria o de desenvolvimento pela aceitação, principalmente no tocante à inserção econômica internacional do país (FONSECA Jr, 1998). Praticar as reformas conforme receitado, esvaziar o papel central ocupado pelo Estado na economia e tratar de atrair, pelo bom comportamento, o investimento externo ansioso pela parceria entre baixo risco e alto lucro. Os planejadores e os dirigentes da política externa brasileira no primeiro governo Cardoso viam que, somente dessa forma, o Brasil teria concedido o seu direito a uma consideração mais alta nas relações políticas e econômicas internacionais.

Mesmo Gelson Fonseca Jr., que define a autonomia pela participação como marca da política externa brasileira da década de 1990, admite que no processo de buscar legitimidade nas relações internacionais, uma das dimensões "nasce da 
maneira como cada país lida com temas indicados, o que se torna, assim, um dos fatores que servem para definir as possibilidades e o nível de participação legítima que pode alcançar no sistema internacional" (FONSECA Jr, 1998). E mais, que a primeira tarefa da diplomacia seria de natureza didática, não buscando a síntese do interesse nacional, mas "ensinando" os atores nacionais a conviver e aceitar com as novas regras internacionais. Todavia, ele próprio também aponta que o Brasil continuava considerando o desenvolvimento como tema "inescapável" da sua agenda internacional.

As crises financeiras do final dos anos 90 demonstraram que essa estratégia era falha. Mesmo aplicando uma política fiscal restritiva, privatizando setores importantes da economia nacional e implementando reformas liberalizantes, todas iniciativas contidas no receituário do chamado "Consenso de Washington", o Brasil foi fortemente afetado pelos efeitos da crise econômica e alcançou resultados medíocres em termos de desenvolvimento e crescimento econômico. Todavia, o cerne da estratégia do plano plurianual, a estabilidade monetária, se mostrava bastante consistente.

Ademais, a modernização produtiva que teria como conseqüência uma inserção competitiva no cenário global também não se deu de forma a promover mudanças significativas na estrutura produtiva nacional. Segundo Machado, nos anos 90 percebeu-se duas modalidades de modernização no Brasil, uma centrada em processos de racionalização e introdução de inovaçôes organizacionais ou novas formas de gestão - terceirização, abandono de linhas de produtos com custos não competitivos, substituição de fornecedores locais por importados - e outra referente à modernização da pauta de consumo, seja pela entrada de oligopólios internacionais que miravam o mercado interno ou por conta da abertura comercial (MACHADO, 2008). Cabe mencionar que o coeficiente de importaçôes da indústria de transformação brasileira apresenta um salto na década de 1990, subindo de 4\% em 1991 para 13\% em 2000 - preços constantes de 2000 -, passando de 9,6\% em 1996 para 13,97\% em 99 (LEVY \& SERRA, 2009). Esse processo de modernização, ainda segundo Machado, "não redunda na criação e consolidação de uma estrutura produtiva industrial que fosse capaz de gerar um núcleo endógeno de inovação"(MACHADO, 2008).

Os efeitos dessa linha de ação sobre o mercado de trabalho também foram perversos. Houve um acréscimo de quase $50 \%$ no nível de desemprego entre janeiro de 1996 e dezembro de 1999 na região metropolitana de São Paulo, enquanto o rendimento médio real trimestral, no mesmo período, caiu mais de $10 \%$, conforme dados da pesquisa de emprego e desemprego do DIEESE. Por fim, os efeitos sobre o balanço de pagamentos, seja por conta do aumento das importações também estimulada pela política cambial da época - ou pela remessa de lucros e dividendos das empresas internacionais que atuavam no Brasil e que, conforme Cervo, juntamente com a especulação financeira, se tornavam uma nova via de dependência, aumentavam a vulnerabilidade externa do país (CERVO, 2002). 
Assim, a negligência da política externa pelo PPA 1996-1999 e a obediência servil aos receituários hegemônicos que ecoaram em diversos países na América do Sul mostravam-se equivocados. O segundo governo Cardoso, por outro lado, encarou com mais sobriedade a realidade internacional, proferindo um discurso de cautela com relação aos efeitos nefastos de uma globalização assimétrica ${ }^{l}$. E o plano plurianual 2000-2003, refletindo esses ajustes, buscou inovaçôes nesse sentido, resgatando o papel da política externa como elemento importante para a estratégia de desenvolvimento esboçada pelo governo.

\section{PPA 2000-2003: um novo planejamento e o resgate da política externa}

O plano plurianual passou por uma reformulação a partir da promulgação do Decreto 2.829, ao final de 1998, que estabeleceu novas regras para a sua elaboração e gestão. Organizando toda a ação de governo em torno de programas, os quais deveriam ser desenhados para enfrentar um problema específico na sociedade, o PPA passava a ter uma identificação total com os orçamentos anuais, sendo, na sua parte tática, considerado como um grande orçamento de quatro anos, sem expressar com clareza as prioridades estabelecidas pelo governo (Ipea, 2008).

Ainda que não expressasse diretamente no conjunto amplo das ações de governo, o PPA 2000-2003 apresentava uma orientação estratégica composta por seis grandes diretrizes, desdobradas em 28 objetivos de governo. Cabe ressaltar que duas das diretrizes que compunham as orientaçôes estratégicas do plano não foram projetos do executivo, mas propostas do Congresso Nacional que acabaram incorporadas no plano de governo.

A estabilidade econômica continuava em destaque. O sucesso na garantia do controle da inflação deveria permanecer como trunfo essencial para os próximos quatro anos. Frente aos impactos nefastos sobre o mercado de trabalho que se verificou no período anterior, expostos acima, a segunda diretriz tratava da promoção do desenvolvimento sustentável e da geração de emprego e oportunidades de renda.

Combater a pobreza, promover a cidadania e a inclusão social e consolidar a democracia e a defesa dos direitos humanos compunham as diretrizes iniciais enviadas pelo governo ao Congresso Nacional. Garantir a estabilidade e buscar o resgate social numa sociedade severamente afetada pelas crises financeiras do final dos anos 90 era a agenda do segundo governo Cardoso. Reduzir as desigualdades inter-regionais e promover os direitos de minorias vítimas de preconceito e discriminação foram as duas diretrizes enxertadas pelo congresso nacional ao plano plurianual.

1 Em seu discurso na abertura do debate geral da 56a. sessão da assembléia Geral da ONU, em 2001, o então presidente Fernando Henrique Cardoso denuncia os problemas de uma globalização assimétrica, que deveria ser contraposta por uma globalização solidária. 
Dentre os 28 objetivos de governo, destacam-se, por fazerem referência explícita as relações internacionais do país, atingir 100 bilhōes de dólares de exportação até 2002 e fortalecer a participação do país nas relações econômicas internacionais. A política externa voltava a constar do planejamento do desenvolvimento nacional, sendo elemento importante das orientações estratégicas do segundo governo Cardoso.

O PPA enfatizava a importância da Organização Mundial do Comércio $\mathrm{OMC}$, e as negociações patrocinadas pela organização deveriam ocupar lugar especial na política de comércio exterior brasileira. Além disso, inseria linhas de financiamento à exportação, açôes de suporte aos setores exportadores, além de desenvolvimento de uma cultura exportadora no empresariado nacional.

Segundo dados do Banco Central, o Brasil fechou o ano de 2002, contudo, com pouco mais de 60 bilhões de dólares em exportações. Apenas em 2005 o balanço de pagamentos apresentou exportações anuais acima de 100 bilhões de dólares, chegando a 118,3 naquele ano, depois de ter alcançado aproximadamente 96,5 bilhôes de dólares em 2004. Obviamente, o aumento do preço das commodities no mercado internacional contribuíram bastante nessa escalada, que apresentou um salto de $21 \%$ entre 2003 e 2002, e mais 32\% em 2004 com relação aos resultados obtidos no ano anterior. Todavia, o PPA não apresentava outras metas que pudessem expressar mais a influência direta das ações de governo sobre dinâmica exportadora. Volume exportado, diversificação da pauta exportadora, número de empresas exportadoras ou participação brasileira no comércio internacional não são mencionados.

Segundo as orientações estratégicas do PPA 2000-2003, o respeito e a credibilidade internacional do Brasil abriam caminho para aumento da sua participação nas relações econômicas internacionais e na discussão dos grandes problemas mundiais. Alinhado com o discurso do presidente que apontava para os efeitos da globalização assimétrica, após a crença kantiana no multilateralismo internacional ter se arrefecido, o plano plurianual defendia a participação do Brasil nas discussões da nova ordem econômica mundial que se insinuava após as graves crises financeiras da década de 1990. Apontava-se com preocupação para a desigualdade entre as nações, e aos efeitos desiguais, prejudiciais aos países em desenvolvimento, que as crises produziram e que a globalização, por si só, não equacionava (MPOG, 2000).

O plano não se furtava também em apresentar os parceiros-chave do Brasil na consecução da sua estratégia de desenvolvimento. Em primeiro lugar, o Mercosul, que completaria seus dez anos de existência e tinha, até então, apresentado resultados animadores. Em 1991, o Brasil respondia por pouco mais de 12\% das exportações argentinas, e em 1998 as importações brasileiras advindas do país vizinho já representavam mais de $30 \%$ da sua pauta de exportações. As importações argentinas de produtos brasileiros representavam, em 1991, 17,5\% do total das importações do país. Em 1998, esse número era de 22,5\% (COUTO, 2006). 
Cabe lembrar, no entanto, que a abrupta desvalorização do Real nos primeiros meses de 1999, ano em que se elaborava o PPA 2000-2003, tinha gerado uma crise entre os membros do bloco, suscitando dúvidas quanto ao seu futuro. Repercutindo os sinais de crise eminente que se abatiam sobre o ânimo do projeto de integração, o embaixador argentino creditado no Brasil à época, Jorge Hugo Herrera Vegas, escrevera num artigo publicado na Revista Brasileira de Política Internacional RBPI, a respeito da desvalorização do Real naquele ano, que o mal já havia sido feito, mas que era necessária uma coordenação das políticas macroeconômicas intra-bloco para que perturbaçôes dessa natureza não colocassem o Mercosul em perigo (VEGAS, 1999).

Em termos concretos, a desvalorização do real teve impactos consideráveis sobre o comércio entre os dois principais parceiros do Mercosul. Em 1999, houve uma redução de quase $30 \%$ nas exportações argentinas para o Brasil, em relação ao ano anterior. As importaçôes argentinas de produtos brasileiros recuaram também $20 \%$ no mesmo período. Com isso, a definição do Bloco como parceiro preferencial na estratégia de inserção internacional do Brasil e elemento essencial do planejamento do seu desenvolvimento servia, sobretudo, para reafirmar o compromisso brasileiro com o projeto de integração após os questionamentos colocados em pauta pelos vizinhos. Todavia, é num horizonte regional ampliado que o Brasil lançava as sementes mais fecundas da estratégia de desenvolvimento do PPA 2000-2003.

É nesse contexto que começa a se afirmar a América do Sul como plataforma regional preferencial do Brasil. Após um flerte com a região, no início dos anos 90, com a proposta de criação dae uma Área de Livre Comércio da América do Sul - ALCSA, o governo brasileiro, a partir dos anos 2000, assumiu a América do Sul como sua referência regional imediata, em substituição à América Latina ou ao próprio Mercosul, e isto já é declarado no plano plurianual elaborado em 1999. No ano seguinte ocorreria, em Brasília, a primeira reunião de presidentes dos países da América do Sul.

Em terceiro lugar, o objetivo do governo priorizava as relações com a União Européia. De outra parte, não citava nominalmente os Estados Unidos ou a Alca, mas afirmava que "o Brasil quer participar de um processo mais amplo de integração, que permitirá a criação de um espaço econômico no continente, marcado pelo equilíbrio de vantagens e por verdadeiro sentido de cooperação"(MPOG, 2000). Destacava, no entanto, os esforços para diminuir as barreiras tarifárias às exportações brasileiras, discriminando os casos do aço, suco de laranja, a carne e o açúcar, parte importante das quais se erguiam justamente no mercado norte-americano.

Por fim, revelava que o governo deveria buscar alternativas para proteger o país das crises financeiras internacionais. Assim, propõe a criação de mecanismos multilaterais que pudessem reduzir as turbulências internacionais e "permitir ao Brasil participar das discussões sobre os rumos da economia mundial" (MPOG, 2000). 
Nesse sentido, há um resgate da política externa no PPA 2000-2003 desde o reconhecimento de sua importância para concretizar os avanços necessários ao desenvolvimento. As crises financeiras internacionais do final dos anos 90 haviam mostrado que não bastava apenas seguir as regras internacionais postas, mas também precisava-se tratar de modificá-las. A América do Sul, frente à instabilidade do Mercosul, revelava-se como plataforma regional preferencial para o Brasil se preparar para os desafios de uma inserção competitiva internacional.

\section{PPA 2004-2007: a política externa para a promoção do Consumo de Massas e a formação de novas parcerias}

A transição do Governo Cardoso para o Governo Lula envolveu-se de grande expectativa por conta da mudança que se alardeava. Enquanto assumia as ações orçamentárias dispostas na Lei Orçamentária Anual proposta pelo executivo no ano anterior e a estrutura programática do PPA 2000-2003, o novo governo ao mesmo tempo desconsiderava os seus pressupostos estratégicos, valendo-se da fraca amarração entre as esferas estratégica e tática/operacional.

Notadamente, era a primeira transição de governo desde que se assumia o Plano Plurianual, além de um mero dispositivo constitucional, como o principal instrumento do planejamento brasileiro, a ferramenta de ligação entre as intenções de médio prazo e a operacionalidade da máquina pública no curto prazo. A elaboração do novo plano ganhava, portanto, a atenção especial do novo grupo dirigente e até dos movimentos sociais organizados que tinham uma ligação histórica com o Partido dos Trabalhadores.

Assim, e alinhado com as experiências administrativas petistas em administrações municipais e estaduais, pretendeu-se construir um plano de forma participativa, com o "envolvimento direto da sociedade". As relações formais, institucionalizadas, do Governo com a sociedade, nas figuras dos conselhos nacionais setoriais, ficaram em segundo plano. Em destaque, uma participação assembleística nos 26 estados da federação e do Distrito Federal, juntando representantes dos governos estaduais e da sociedade civil organizada, num total de mais de duas mil entidades representadas, para debater e definir os desafios centrais do governo que deveriam estar expressos no plano. Segundo o próprio texto introdutório do PPA, "a construção e a gestão do Plano a partir de um amplo debate com a sociedade busca a implantação de um novo padrão de relação entre Estado e sociedade, marcado pela transparência, solidariedade e corresponsabilidade"(MPOG, 2004).

A proposta de lei para o Plano Plurianual 2004-2007 foi entregue pelo Executivo no Congresso Nacional no final de agosto de 2003, como previa o decreto 2.829/98. Sua configuração compunha-se de uma estratégia de longo prazo baseada na promoção de um mercado interno de consumo de massa, com três grandes objetivos de governo claramente demarcados nas áreas social, 
econômica e institucional. Esses objetivos desdobram-se em trinta desafios, esses o principal aspecto debatido nos fóruns de participação social. E, por fim, cada desafio desdobrava-se em diretrizes de ação que seriam posteriormente vinculados aos programas e ações do PPA e das leis orçamentárias anuais.

A estratégia de desenvolvimento de longo prazo ganhava destaque neste PPA. Ausente no plano anterior, parte de um diagnóstico que identificava os principais problemas a serem enfrentados, dentre os quais se destacava a concentração social e espacial da renda e riqueza, pobreza e exclusão social, desrespeito aos direitos fundamentais da cidadania, degradação ambiental, baixa criação de empregos e "as barreiras para a transformação dos ganhos de produtividade em aumento de rendimentos da grande maioria das famílias trabalhadoras”. Prenuncia da seguinte forma a estratégia formulada:

Inclusão social e desconcentração de renda com vigoroso crescimento do produto e do emprego; crescimento ambientalmente sustentável, redutor das disparidades regionais, dinamizado pelo mercado de consumo de massa, por investimentos, e por elevação da produtividade; redução da vulnerabilidade externa por meio da expansão das atividades competitivas que viabilizam esse crescimento sustentado; e fortalecimento da cidadania e a democracia (MPOG, 2004).

No que mais diz respeito às preocupações do presente artigo, a estratégia de longo prazo traz uma projeção importante de redução da vulnerabilidade externa, o que se mostrava central para um país que ainda sofria conseqüências das crises internacionais do final da década de 1990 e da fuga de capitais que ocorrera em 2002, pela sombra da possibilidade real de eleição de candidato que já tinha defendido a moratória da dívida e pela realidade das fragilidades das contas externas do país.

Sua implicação imediata se traduziu no esforço direcionado ao aumento das exportações, para o que o plano sugeria o caminho da diversificação da pauta exportadora do país, a conquista de novos mercados, além da maior presença dos produtos brasileiros em mercados já consolidados, sem entretanto indicar metas quantitativas para tanto. Nesse ponto, a estratégia de desenvolvimento já fazia menção ao Mercosul e aos demais países da América do Sul, para os quais antevia uma integração comercial sólida.

A estratégia de desenvolvimento visava também ampliar a competitividade da produção nacional pela via dos investimentos em infra-estrutura, particularmente nas áreas de logística de transportes, energia e comunicações. O aumento dos investimentos, tanto nos setores de forte emprego de mão-de-obra quanto, e principalmente, em ciência, tecnologia e inovação estava também no cerne do modelo de crescimento por consumo de massas, que traria benefícios, segundo a estratégia de desenvolvimento apontava, sobre o balanço de pagamentos do país.

A questão chave do modelo de crescimento por consumo de massas está na transmissão dos ganhos de produtividade da economia para o rendimento das 
famílias trabalhadoras, que aumentaria a massa salarial do país que se direcionaria, naturalmente, aos setores mais modernos da economia e, por conseqüência, aumentaria a competitividade da produção nacional pelos ganhos de escala auferidos pela expansão do mercado interno. Ganhos de produtividade também seriam alcançados com investimentos em inovação que deveriam seguir-se ao crescimento dos ganhos dos setores modernos da economia produtores de bens de consumo de massas. Ao ganhar eficiência pelo aumento da escala conferida pelo mercado doméstico, aproximar-se-ia das conquistas de mercados externos, devido aos benefícios do primeiro estágio. Haveria, portanto, um circuito positivo entre investimentos, ganhos de produtividade, transmissão desses ganhos às famílias trabalhadoras, aumento da demanda que impulsionaria, por sua vez, novos investimentos, com lugar especial à inovação.

Assim, os benefícios para a balança comercial brasileira dar-se-iam nos dois sentidos. Os impactos dos ganhos de produtividade seriam benéficos aos setores exportadores como garantiriam uma maior competitividade da produção voltada ao mercado interno que concorre com as importaçóes. De outro lado, dado que grande parte da renda das famílias trabalhadoras é comprometida com alimentos, moradia, educação e saúde, não pressionariam as importações.

Denota-se aí uma contradição intrínseca ao modelo. Se a demanda da camada menos abastada da população, ao ser incluída no mercado, seria direcionada aos setores mais modernos, ela poderia sim exercer pressão sobre as importações. Não se poderia garantir que o abastecimento dessa demanda se daria exclusivamente pela produção interna, ainda mais em setores com componentes tecnológicos que não são fabricados no país. Dados apontam para um aumento da participação de importados no consumo doméstico, especialmente em material eletrônico e de comunicações, dentre os quais se pode incluir computadores pessoais e telefones celulares, que tiveram uma grande expansão no consumo nos últimos anos. $\mathrm{O}$ conteúdo importado desses equipamentos subiu de $38,1 \%$, em 2003 , para $66,3 \%$ em 2008. Entre 2003 e 2007, a participação dos importados no consumo doméstico aumentou de $14 \%$ para $21,3 \%$, alcançando $23,7 \%$ em $2008^{2}$.

Todavia, ainda assim os resultados alcançados para o comércio exterior do período ficaram acima das metas estabelecidas no plano plurianual. Em 2007, a soma das importações e exportações brasileiras foi de 306,97 bilhões de dólares, $46,18 \%$ maior do que a meta prevista em 2003 e 136\% maior do que o realizado naquele ano. Em 2003, o saldo da balança comercial, que era de pouco menos de US \$ 25 bilhões, passou de U\$ 33 bilhões em 2004, US $\$ 42$ bilhões em 2005, US \$ 43 bilhões em 2006, recuando para 40 bilhões em 2007. As metas estabelecidas pelo governo consideravam saldos superavitários entre 17 e 21 bilhões de dólares anuais para o período.

2 Fatia de importados no consumo atinge 23,7\% em 2008, Valor Econômico, 13/2/2009. 
Consolidava-se, portanto, os ensaios da correção de rumos que passaram a ocorrer com a corrente comercial brasileira, principalmente pós-crise de 1999 . Segundo Amado Cervo, com Cardoso, o comércio exterior tinha adquirido função de variável dependente da estabilidade financeira, deixando de lado duas de suas funçōes históricas estratégicas de promotor da produção interna e de formação de reservas de capital externo. Ainda em Cardoso, no entanto, face aos efeitos das crises internacionais que haviam afetado o país, esse papel era revisado, ao mesmo passo em que se ensaiava a promoção do paradigma do Estado Logístico no país ${ }^{3}$.

Em termos de reservas internacionais, os resultados alcançados, com reflexos na redução da vulnerabilidade externa do país também foram expressivos. Em 31 de dezembro de 2007, as reservas internacionais divulgadas pelo Banco Central do Brasil - BACEN, somavam mais de US\$ 180 bilhões, número que no último dia do ano de 2003 estava um pouco abaixo de US $\$ 49,5$ bilhóes (em 2002, excluídos os empréstimos do FMI, esse valor era de US $\$ 16,3$ bilhões, aproximadamente). Em fevereiro de 2008, o BACEN divulgaria que o Brasil passava à condição de credor internacional, posição alcançada ainda em janeiro, quando os ativos brasileiros no exterior superaram a dívida externa pública e privada em US $\$ 4$ bilhōes. Em abril de 2008, o Brasil seria receberia o grau de investimento pela agência americana de classificação de risco Standard \& Poor's.

Abaixo da estratégia de desenvolvimento de longo prazo, revelam-se três grandes objetivos (ou mega-objetivos) do governo que orientavam o restante do plano. O primeiro dizia respeito à inclusão social e redução das desigualdades sociais, que se desdobrava em dez desafios específicos. O segundo megaobjetivo apresentava crescimento com geração de trabalho, emprego e renda, ambientalmente sustentável e redutor das desigualdades sociais, com 11 desafios arrolados. Por fim, o terceiro ressaltava a promoção e expansão da cidadania e fortalecimento da democracia, com nove desafios enumerados.

Este último traz um desafio específico diretamente relacionado com a política externa a ser empreendida no período: "Promover os valores e os interesses nacionais e intensificar o compromisso do Brasil com uma cultura de paz, solidariedade e de direitos humanos no cenário internacional." Em seu enunciado nada que revelasse qualquer linha específica do novo governo que então, com cerca de seis meses no poder, tentava imprimir na sua relação com o mundo.

$\mathrm{Na}$ sua descrição, porém, os pontos principais da linha adotada na política externa de Lula já estavam presentes. Partia de uma crítica direta ao relacionamento do Brasil com seus vizinhos sul-americanos, no qual teria tido uma postura apenas discreta, enquanto considerava tímida a posição adotada até então nas relações

\footnotetext{
3 A conceituação do paradigma de Estado Logístico é apresentada por Amado Cervo, caracterizando-se pelo resgate da autonomia decisória em política externa, promoção e proteção dos interesses nacionais e apoio estatal à internacionalização das empresas nacionais. O Estado atuaria na obtenção de e na ampliação dos mercados externos e combate aos subsídios e barreiras comerciais que afetam a produtividade do produto nacional. Ainda, há atenção especial às questôes de dependência tecnológica, com o Estado atuando na promoção da inovação produtiva. (CERVO, 2003a)
} 
com os parceiros comerciais, nas negociações de acordos multilaterais e de blocos econômicos.

Em seguida, para reverter o quadro anterior, o plano defendia uma articulação regional que buscasse a complementaridade que favoreceria o "desenvolvimento harmônico" do Brasil e dos países do continente. Com relação aos países do centro, ressaltava que se devia manter uma relação equilibrada com os países que integravam o NAFTA, a UE e o bloco asiático em torno do Japão. Ainda, antevia uma maior aproximação do Brasil com China, Índia e Rússia, além dos países africanos, em particular os de língua portuguesa e a África do Sul (MPOG, 2004).

Nesses aspectos, chama a atenção, em primeiro lugar, um reconhecimento institucional de uma consideração diferenciada do México, enquanto participante do NAFTA, dos demais países da América do Sul. A "América Latina", cada vez mais, deixa de fazer sentido enquanto sujeito das relaçôes internacionais do Brasil, porquanto deixa de fazer parte das consideraçóes estratégicas dos atores (MARTINS, 2004), e mesmo como objeto de estudo desde uma perspectiva brasileira ou sul-americana.

Ainda que tenha ocorrido antes da aprovação formal do plano, a iniciativa de articulação trilateral entre Índia, Brasil e África do Sul, com a formação do IBAS, já na administração Lula, tentava estreitar os laços de relacionamento entre os três países, destacados no desafio estratégico do PPA. Na mesma linha situavam-se as tentativas de conferir uma instrumentalidade prática ao conceito de BRICs, a partir do que o Brasil buscava uma articulação com China e Rússia, além da Índia, insinuando interesses comuns frente aos desafios impostos no cenário internacional.

Por fim, mas não menos importante, preconizava a reforma e "democratização" do Conselho de Segurança das Naçôes Unidas, enfatizando como um dos objetivos da política externa brasileira a presença do Brasil enquanto membro permanente num conselho de segurança ampliado. A propósito, cabe ressaltar os esforços empreendidos pelo Brasil pela reforma do principal fórum político mundial. A formação do G4, entre Brasil, Alemanha, Índia e Japão, que se apoiavam mutuamente para garantirem um assento permanente no Conselho, data de 2004. Seus resultados, no entanto, foram inexpressivos em termos práticos.

Em sete diretrizes de ação dentro do objetivo específico, se dava maior luz aos componentes principais do desafio proposto. Logo na primeira, como tem sido a tônica do Governo atual, era destacada a intensificação das relações e da cooperação do Brasil com os países da América do Sul e, em seguida, com os demais países em desenvolvimento. Mais uma vez, reforçava-se a imagem da sulamericanidade com a qual o Brasil passou a cunhar sua identidade internacional a partir dos anos 90 .

Em segundo lugar, uma defesa do multilateralismo e do direito internacional. Assim como defende o aperfeiçoamento da legitimidade e representatividade dos organismos internacionais, o Brasil também passou a defender uma 
institucionalização do diálogo multilateral na própria América do Sul, com a proposta da Comunidade Sul-americana de Nações - Casa, que viria a ser formalmente criada em 2008 como União Sul-americana de Nações - Unasul.

Em terceiro lugar, apresentava-se o país com a intenção de reforçar o combate aos ilícitos transfronteiriços em todas as suas formas. As pressōes pós-11 de Setembro de 2001 com relação à tríplice fronteira, por parte dos Estados Unidos, pressōes também com relação ao combate à pirataria e as preocupações com o tráfico de drogas e a seus reflexos na violência dos grandes centros urbanos do país justificavam tal posição.

A quarta diretriz foi dedicada às questóes atinentes à defesa do meio ambiente e desenvolvimento sustentável no plano internacional. O Brasil, como ator interessado e sujeito a pressões nessa área envoltas ao tema da floresta amazônica, mostrava-se preocupado em se apresentar ativo internacionalmente.

Apenas a quinta diretriz, embora não haja uma hierarquia entre elas, ressaltava o relacionamento do país com seus parceiros de Mercosul. Preconizava-se um fortalecimento das relações entre os países do bloco, valorizando outros aspectos além das questôes comerciais, particularmente a integração social e cultural. Enquanto o foco é América do Sul, o Mercosul é uma plataforma de ensaio dessa integração regional, e se o objetivo é a construção de um bloco regional, ou de uma união de nações sul-americanas, a vertente meramente comercial é limitada.

As duas últimas diretrizes eram mais reiterações do discurso histórico diplomático do que efetivamente prioridades da política externa para o período em voga. Diziam respeito ao fortalecimento da atuação do país nos fóruns multilaterais, com ênfase "na promoção de uma cultura de paz e de direitos humanos" e da divulgação dos acordos internacionais que o país é signatário e o compromisso de acompanhar seu cumprimento.

Há, portanto, um alto grau de coerência entre o disposto no Plano Plurianual e as linhas de atuação implementadas pelo primeiro governo Lula. A priorização da América do Sul enquanto foco da política externa, presente desde os primeiros discursos do presidente eleito e do chanceler Celso Amorim, ganhava destaque. Da mesma forma, o novo patamar de relacionamento com os BRICS e África do Sul estavam em linha. Por fim, os esforços em torno da diminuição da vulnerabilidade externa do país, seja pela ampliação das exportações, acumulação de divisas ou atração de investimentos fazem parte de uma estratégia de longo prazo embasada na consolidação de um mercado de consumo de massas que, todavia, demanda muito mais do que quatro anos para ser implementada em sua plenitude.

\section{PPA 2008-2011: o foco na América do Sul e a nova agenda dos biocombustíveis}

O Plano Plurianual para o período 2008-2011 começou a ser moldado com o lançamento do Programa de Aceleração do Crescimento - PAC, logo no início 
do segundo mandato do presidente Lula da Silva. Com uma pesada agenda de investimentos em infra-estrutura, boa parte dos recursos discricionários do governo, ao se construir o plano, já tinham uma destinação previamente programada.

As transferências de renda que atingiram, apenas com o Bolsa Família, mais de 11 milhões de famílias ainda em 2007, ficaram no centro de uma agenda social que ladeia o PAC na conformação estratégica do plano. E, a completar o tripé de sustentação do PPA 2008-2011, dá-se destaque ao Plano de Desenvolvimento da Educação - PDE, que abrange desde a educação básica e alfabetização e educação continuada para jovens e adultos, até o ensino superior, passando pelo ensino profissional e tecnológico. O PPA 2008-2011, trata, portanto, de reunir e forjar, a posteriori, uma agenda estratégica baseada em iniciativas previamente lançadas pelo governo. Faz-se um esforço de amarração, a direcionar agendas independentes rumo a um mesmo norte.

No núcleo da amarração, novamente a estratégia de crescimento pela via da ampliação do mercado de consumo de massas, herança consistente do período anterior, considerando-se que este mecanismo exige prazo mais longo para aprimorar o seu funcionamento. Persiste a ênfase no ciclo virtuoso a ser gerado por investimentos, inovação, aumento da produtividade, distribuição dos ganhos de produtividade aos trabalhadores, aumento da massa salarial, ganhos de escala e novos investimentos. A visão do componente internacional da estratégia continua presente, reforçando o papel da Ciência, Tecnologia e Inovação para um posicionamento competitivo do Brasil no contexto internacional na sua centralidade para as políticas de promoção de investimento produtivo.

A dimensão territorial do desenvolvimento ganha espaço dentro da nova estratégia. A valorização das realidades sub-regionais e seu papel na construção de uma agenda de desenvolvimento do país ecoa no discurso oficial. A incorporação da dimensão territorial à estratégia promoveria, entre outros, um apoio à integração sul-americana e à inserção competitiva autônoma no mundo globalizado (MPOG, 2008a).

Considerar o território como suporte à integração sul-americana tem, a princípio, dois pontos positivos. $\mathrm{O}$ primeiro diz respeito à própria assimilação da integração do Brasil com a América do Sul como parte da estratégia brasileira de desenvolvimento. É reconhecer que se integrar aos vizinhos é benéfico ao Brasil e transmite a idéia de que a região tem um papel a cumprir nos caminhos a serem trilhados pelo processo de desenvolvimento nacional. Em segundo lugar, de ordem mais prática, representa a disposição de preparar o território para essa integração. Dotar o território de instrumentos, de técnicas, que facilitem e tornem mais velozes os fluxos intra-continentais, aproximando as distâncias. Pensar, ademais, cidades ou regiões a oeste do país que sirvam de suporte a essa virada ao interior, desconcentrando o desenvolvimento brasileiro ao oferecerem serviços de qualidade no interior do país, lastreadas por infra-estrutura compatível que prepare uma logística capaz de absorver esse aumento de fluxo (MPOG, 2008b). 
O cenário macro-econômico da estratégia de desenvolvimento prevê, para o período, um saldo em conta corrente declinante em termos de percentuais do PIB. Previu-se, para 2008, 0,4\% do PIB, caindo 0,1\% a cada ano, chegando em 2011 com saldo positivo de $0,1 \%$ do Produto Interno Bruto. Obviamente, as previsões foram feitas antes da grave crise internacional que se abriu no segundo semestre de 2008 ter se instalado, cujos impactos sobre o balanço comercial brasileiro ainda não são consenso entre os analistas, além da esperada redução no fluxo total de comércio. Todavia, segundo dados do Banco Central, entre janeiro e outubro de 2008, o saldo brasileiro de transações correntes já foi negativo em 1,83\% do PIB, tendo alcançado, em 2007, saldo positivo de apenas $0,13 \%$ do PIB, frente 1,27 do ano anterior. Para 2011, o governo apresenta meta de elevar a participação brasileira para 1,3\% do comércio internacional, uma meta um pouco mais elaborada que as anteriores, com as exportações alcançando US $\$ 230$ bilhões.

No lugar dos 30 desafios do PPA 2004-2007, o novo plano apresenta 10 objetivos de governo. Entre eles, "Fortalecer a inserção soberana nacional e a integração sul-americana”. Em termos de política externa, esse é o grande destaque do novo plano, que concebe a integração sul-americana como objetivo transversal do governo, formalizando o destaque que a região ganhou ao longo do primeiro ano do governo Lula.

O objetivo de governo é respaldado pelas iniciativas já em curso e não apresenta, para este tema, nenhuma novidade. Assim, sublinha as ações levadas a cabo pelo governo nos quatro anos antecedentes, como o Programa de Substituição Competitiva de Importações para incentivar a exportação dos países sulamericanos para o Brasil. Todavia, as iniciativas não se bastam na área comercial, contemplando, comunicações, saúde, saúde animal, ciência e tecnologia, meio ambiente e educação, além do programa de desenvolvimento da faixa de fronteira capitaneado pelo Ministério da Integração Nacional.

Os projetos brasileiros de infra-estrutura que estabelecem ligações com o continente sul-americano são destacados. A maioria deles consta entre os projetos prioritários da Iniciativa para a Integração da Infra-estrutura Regional Sulamericana - IIRSA, implicando um reconhecimento da importância da agenda da iniciativar $\underline{23}$. Dos dez projetos do setor de transportes citados, sete fazem parte daquela agenda. Além desses, os dois projetos de comunicações, a cooperação em torno da exportações via remessas postais para pequenas e médias empresas e a promoção do roaming internacional de telefonia celular na região são também projetos da agenda de implementação consensuada da IIRSA, apresentada em 2004, na terceira reuniāo de presidentes da América do Sul, realizada em Cuzco, no Peru.

Ainda, o plano posiciona-se na defesa de uma ordem internacional mais justa e solidária, destacando a Ação contra a Fome e Pobreza, lançada em 2004. Mais uma vez, como tem sido uma constante na política externa do governo Lula, ressalta a importância da reforma da ONU, particularmente do seu Conselho de 
Segurança, destacando a articulação brasileira, até agora frustrada, em torno do G4, que já sofreu a deserção formal do Japão. Na mesma linha, a sua participação no Haiti também é lembrada.

No mais, defende a formação de uma nova geografia comercial e destaca o papel brasileira na formação do G-20. Invoca a relevância da cooperação Sul-Sul, com atenção especial ao fórum de diálogo Índia-Brasil-África do Sul - IBAS, seguindo a linha de prioridades destacadas no PPA 2004-2007. Por outro lado, a China e Rússia, que conformam, junto com Brasil e Índia, os BRICs, não são citados pelo novo plano, substituídas por uma breve menção à Ásia, considerada novo centro dinâmico da economia mundial.

Além dessa marcante ausência, o que de mais novo consta no PPA 2008-11 é o tópico referente aos biocombustíveis. A degradação ambiental e a conseqüente mudança do clima e seus impactos são encarados como desafios globais que contarão com "postura ativa" da diplomacia brasileira. Um projeto de desenvolvimento sustentável é aclamado e, nele, ganham importância os combustíveis renováveis, cujos benefícios devem ser compartilhados com os demais países.

O estouro e o desenrolar da crise econômica, não limitada ao mundo das finanças, tratou de colocar às sombras muitos dos assuntos que não tivessem como foco de atenção justamente o debate em torno das soluções frente à recessão que ameaça o globo. Todavia, o cenário atual da inauguração da administração Obama nos Estados Unidos e a agenda política conflitiva herdada dos Estados Unidos no Oriente Médio, particularmente no Iraque e no Afeganistão, podem representar um novo fôlego às discussōes acerca de substituição paulatina da dependência energética do petróleo, respaldada pelas suas implicaçôes ambientais, e se poderá verificar se a aposta brasileira na temática foi acertada e se os esforços, além dos discursos, foram feitos, e se foram suficientes.

\section{Conclusão}

Neste artigo, apresentou-se o modo com que a política externa brasileira vem sendo tratada nos últimos planos governamentais de médio prazo. A expectativa foi, em primeiro lugar, indicar a existência de uma frente de pesquisa inexplorada nos estudos sobre política externa brasileira. Vê-se, por exemplo, que toda a programação plurianual de recursos para investimentos públicos ou a previsão orçamentária para o período de quatro anos dos órgãos públicos, seja nos ministérios, nas autarquias federais ou nas empresas estatais podem emprestar dados para a análise concreta das prioridades de governo e de suas linhas de ação internacional.

Outrossim, buscou-se demonstrar que a política externa empreendida no período guardou coerência com as orientações estratégicas estabelecidas nos planos plurianuais. Mesmo no Plano Plurianual do período 1996-1999, no qual as orientações estratégicas não fazem referência às linhas prioritárias de política externa 
a serem seguidas, há uma consonância com o que de fato se verificou na maior parte do período, que significava seguir as linhas políticas ortodoxas hegemônicas, que vincularia responsabilidade à imagem internacional do país e o credenciaria na arena global. Era a ausência de intencionalidade de se propor uma política externa autônoma que se fazia presente no planejamento governamental.

Por outro lado, as principais parcerias a serem estimuladas pelo governo estavam expressas nos planos seguintes. Desde a delimitação da América do Sul, que se apresentava no plano 2000-2003 e se consolidou nos planos posteriores, mostrando que essa opção não é nova no governo Lula, até a aposta na projeção internacional da temática dos biocombustíveis, no PPA 2008/2011, fizeram parte das orientaçôes estratégicas do governo, que deveriam subsidiar as açôes setoriais e estimular a cooperação técnica e coordenação política entre os países ou blocos parceiros.

Em terceiro lugar, se considera que, embora a estratégia de desenvolvimento não tenha saído do horizonte, o modo como se percebia que a política externa poderia contribuir para o seu alcance variou nos diferentes planos que se sucederam de 1996 até o PPA 2008/2011. A modernização e o desenvolvimento sempre constaram dessa agenda, mas mesmo quando houve a reeleição do principal governante, e principalmente na passagem de governo entre grupos politicamente opostos, as estratégias eram claramente distintas e guardavam lugares e temas prioritários específicos para a política externa brasileira.

A análise sistemática das orientações estratégicas dispostas nos últimos quatro planos plurianuais também pode contribuir para o debate acerca do grau de continuidade e ruptura em termos da política externa tanto planejada quanto efetivamente implementada por Cardoso e Lula. Mesmo que grandes objetivos permaneçam na agenda, isso não implica necessariamente uma continuidade automática, dado que a estratégia de desenvolvimento pode se traduzir em iniciativas ou açôes diferenciadas a ponto de se perceberem rupturas no tratamento de determinado tema.

Por fim, a análise dos planos plurianuais permite visualizar múltiplos elementos que podem revelar o grau de racionalidade da política externa. É dizer, em primeiro lugar, que a política externa é transversal à ação governamental, para a qual devem convergir os demais órgãos da administração pública (KEOHANE \& NYE, 2001). E, num segundo plano, considerar a ação externa como um componente de uma estratégia política mais ampla, na qual vários elementos se complementam em busca de objetivos maiores. Sãos os fins, e não os meios, que devem reger a análise. Nessa linha, a política externa deixa de ser vista como exclusividade do Ministério das Relaçôes Exteriores, mas responde também como a soma das movimentações externas dos diversos órgãos de Estado. O quanto a burocracia internaliza o plano e o tem como norte a ser perseguido, no entanto, resta a ser verificado por pesquisas futuras. 


\section{Referências bibliográficas}

ALMEIDA, Paulo Roberto de. Planejamento no Brasil: memória histórica. Parcerias estratégicas, Brasília, v. 18, n. 1, p. 157-190, 2004

BRASIL. Ipea. Boletim de Políticas Sociais: Acompanhamento e análise. N. 16, 2008.

BRASIL. Ministério do Planejamento, Orçamento e Gestão. O desafio do planejamento governamental. Brasília, 2002. MPOG.

BRASIL. Ministério do Planejamento. Plano Plurianual 1996-1999. Mensagem ao Congresso Nacional. MPOG. Brasília 1996.

BRASIL. Ministério do Planejamento. Plano Plurianual 2000-2003. MPOG. Brasília 2000

BRASIL. Ministério do Planejamento. Plano Plurianual 2004-2007. Mensagem ao Congresso Nacional. MPOG. Brasília 2004.

BRASIL. Ministério do Planejamento. Plano Plurianual 2008-2011. Mensagem ao Congresso Nacional. MPOG. Brasília 2008, a.

BRASIL. Ministério do Planejamento. Estudo da dimensão territorial do planejamento. MPOB, 2008, b.

BERNAL-MEZA, Raúl. A política exterior do Brasil: 1990-2002. Revista Brasileira de Política Internacional [online]. 2002, vol.45, n.1 [cited 2009-04-16], pp. 36-71. Available from: <http://www.scielo.br/scielo.php?script=sci_arttext \&pid=S0034$73292002000100002 \& \operatorname{lng}=$ en $\& \mathrm{nrm}=\mathrm{iso}>$. ISSN 0034-7329. doi: 10.1590/S003473292002000100002 .

CERVO, Amado Luiz. Política exterior e relações internacionais do Brasil: enfoque paradigmático. Revista Brasileira de Política Internacional [online]. 2003a, vol.46, n.2 [cited 2009-04-16], pp. 5-25. Available from: <http://www.scielo.br/scielo.php?script=sci_ arttext $\&$ pid $=$ S0034-73292003000200001\&lng $=$ en $\&$ nrm $=$ iso $>$. ISSN 0034-7329. doi: 10.1590/S0034-73292003000200001.

CERVO, Amado Luiz. Editorial - a política exterior: de Cardoso a Lula. Revista Brasileira de Política Internacional [online]. 2003b, vol.46, n.1 [cited 2009-04-16], pp. 5-11. Available from: <http://www.scielo.br/scielo.php?script=sci_arttext\&pid=S0034$73292003000100001 \& \operatorname{lng}=$ en $\& \mathrm{nrm}=$ iso $>$. ISSN 0034-7329. doi: 10.1590/S003473292003000100001.

CERVO, Amado Luiz. Relações internacionais do Brasil: um balanço da era Cardoso. Revista Brasileira de Política Internacional [online]. 2002, vol.45, n.1 [cited 2009-04-16], pp. 5-35. Available from: <http://www.scielo.br/scielo.php?script=sci_arttext\&pid=S0034$73292002000100001 \& \operatorname{lng}=$ en $\& \mathrm{nrm}=$ iso $>$. ISSN 0034-7329. doi: 10.1590/S003473292002000100001 .

COUTO, Leandro Freitas. O horizonte regional do Brasil e a construção da América do Sul (1990-2005). Dissertação de Mestrado em Relações Internacionais. Brasília: Mimeo, Universidade de Brasília, 2006

COUTO, Leandro Freitas, A Iniciativa para a Integração da Infra-estrutura Regional Sulamericana - IIRSA como instrumento da política exterior do Brasil para a América do Sul. OIKOS - Revista de Economia Heterodoxa. Vol. 1, n. 05.2006

FONSECA Jr., Gelson. A legitimidade e outras questôes internacionais. São Paulo: Paz e Terra, 1998. 
KEOHANE, R. \& NYE, J., Power and Interdependence. 3. ed. New York: Longman. 2001.

LEVY, Paulo Mansur. \& SERRA, Maria Isabel F. Coeficientes de Importação e Exportação na Indústria. Nota Técnica do Ipea

MACHADO, Gustavo Viana. A internacionalização da economia brasileira nos anos 90 . In OIKOS - Revista de Economia Heterodoxa. Ano VII, n. 10. 2008

MARTINS, Estevão de Rezende. O alargamento da Uniāo Européia e a América Latina. Revista Brasileira de Política Internacional [online]. 2004, vol.47, n.2 [cited 2009-04-16], pp. 5-24. Available from: <http://www.scielo.br/scielo.php?script=sci_arttext\&pid=S0034$73292004000200001 \& \operatorname{lng}=$ en $\& \mathrm{nrm}=\mathrm{iso}>$. ISSN 0034-7329. doi: 10.1590/S003473292004000200001.

SARAIVA, Miriam Gomes. As estratégias de cooperação Sul-Sul nos marcos da política externa brasileira de 1993 a 2007. Rev. bras. polít. int. [online]. 2007, vol.50, n.2 [cited 2009-04-16], pp. 42-59. Available from: <http://www.scielo.br/scielo.php?script=sci_ arttext $\&$ pid $=$ S0034-73292007000200004\&lng $=$ en \& $\mathrm{nrm}=$ iso $>$. ISSN 0034-7329. doi: 10.1590/S0034-73292007000200004.

LIMA, Maria Regina Soares de. A política externa brasileira e os desafios da cooperação SulSul. Revista Brasileira de Política Internacional [online]. 2005, vol.48, n.1 [cited 2009-04-16], pp. 24-59. Available from: <http://www.scielo.br/scielo.php?script=sci_arttext\&pid=S0034$73292005000100002 \& \mathrm{lng}=$ en $\& \mathrm{nrm}=\mathrm{iso}>$. ISSN 0034-7329. doi: 10.1590/S003473292005000100002 .

VEGAS, Jorge Hugo Herrera. Impactos da desvalorização do real sobre o comércio entre o Brasil e a Argentina. Revista Brasileira de Política Internacional [online]. 1999, vol.42, n.2 [cited 2009-04-16], pp. 5-17. Available from: <http://www.scielo.br/scielo.php?script=sci_ arttext $\&$ pid $=$ S0034-73291999000200001\&lng $=$ en $\&$ nrm $=$ iso $>$. ISSN 0034-7329. doi: 10.1590/S0034-73291999000200001.

VIGEVANI, Tullo and CEPALUNI, Gabriel. A política externa de Lula da Silva: a estratégia da autonomia pela diversificação. Contexto int. [online]. 2007, vol.29, n.2 [cited 2009-04-16], pp. 273-335. Available from: <http://www.scielo.br/scielo.php?script=sci_arttext\&pid=S0102$85292007000200002 \& \operatorname{lng}=\mathrm{en} \& \mathrm{nrm}=$ iso $>$. ISSN 0102-8529. doi: $10.1590 /$ S010285292007000200002 .

Recebido em 17 de janeiro de 2009 Aprovado em 16 de abril de 2009

\section{Resumo}

Analisando as orientações estratégicas dos últimos quatro planos plurianuais - 19961999, 2000-2003, 2004-2007 e 2008-2011, no artigo, revela-se como a política externa tem sido incorporada no planejamento federal e qual o papel concedido ao setor externo nas estratégias de desenvolvimento empreendidas pelos governos Cardoso e Lula. Demonstra coerência entre a política externa planejada e a efetivamente empreendida, explicitando as diferenças entre as estratégias adotadas e as linhas de ação externa priorizadas. 


\section{Abstract}

Analyzing strategic orientations of the last four plurianual plans - 1996-1999, 2000-2003, 2004-2007 e 2008-2011, the article reveals how foreign policy has been incorporated to federal planning and the role given to the foreign sector in the development strategies undertaken by Cardoso and Lula governments. It demonstrates coherence between the foreign policy planned and that effectively undertaken, explaining the differences between their strategies and the lines of foreign policy priotitezed.

Palavras-chave: Política externa brasileira; planos plurianuais; estratégias de desenvolvimento brasileiro.

Key words: Brazilian Foreign Policy; plurianual plans; Brazilian development strategies. 